\title{
SHIFT WORK AND OCCUPATIONAL STRESS IN HOSPITAL NURSES IN SOFIA
}

\author{
K. Vangelova, I. Dimitrova, I. Cekova, R. Stoyanova \\ National Center of Public Health and Analyses - Sofia, Bulgaria
}

\begin{abstract}
Prevalence of shift work and occupational stress is one of the highest in nursing compared to other sectors. For years Bulgaria is facing nurses'shortage, which contributes to their long working hours. The aim of the study was to follow the working time arrangements, stressors and health symptoms in hospital nurses in Sofia. Methods: The study is cross-sectional and comprised 1292 female nurses of average age $50.0 \pm 10.2$ years from 19 hospitals in Sofia. The anonymous questionnaire was filled, including demographic information, working hours and shift system, with special attention to night work and long working hours, stress and health symptoms. Statistical analysis was carried using SPSS. Results: The shift work, night work, including 5 and more night shifts per month and the extended shifts were common among the studied nurses with the greatest deal of the emergency and intensive care unit nurses, followed by department nurses. The high rates of overtime and second job contributed to long working hours of 51-60 hours per week in 16.9 $\%$ of the nurses and $>61$ hours in $11.1 \%$. About $90 \%$ of the nurses felt under strain and experienced emotional dissonance while working with patients. Work-related stress, night work and long working hours were related to self-rated emotional and physical exhaustion and poor health. Discussion: The work-related stress, night work and the long working hours raise health concerns for occupational health of hospital nurses. Urgent preventive measures are needed to control stress and reduce working hours and night work.
\end{abstract}

Key words: work-related stress, overtime, shift work, hospital nurses

Corresponding author: Katya Vangelova, National Center of Public Health and Analyses, 15 Acad. Ivan Ev. Geshov Blvd, Bg-1413 Sofia, Tel. 028056224, E-mail: k.vangelova@ncpha.government.bg

ACCEPTED: 8 December 2019

\section{INTRODUCTION}

$\mathrm{N}$ ight shift work is wide spread in the health care sector, with the highest rates in the hospitals, often with shift schedules including extended shifts. There are data that the nurses who often work overtime or without proper rest are more susceptible to higher absenteeism and deterioration in their health status [1]. The more hours spent at work, the more prominent certain factors become, including an increased risk of diseases, conflicts, dissatisfaction with work, and leaving the profession; the effectiveness of nursing interventions is also negatively affected.

Prevalence of occupational stress is one of the highest in nursing compared to other sectors [2, 3, 4]. Working as a nurse is intense, decision-rich and includes changing clinical environments with frequent interruptions during tasks $[5,6]$. Their commitment 
and efficiency influence the safety and satisfaction of patients. Nurses who work in emergency and intensive care units take care of people with acute and/ or chronic health problems that require permanent, specialised and highly specific nursing care $[7,8]$. The stress and workloads of emergency and intensive care unit nurses were found to be higher than the stress and workloads of nurses working in clinics [8]. Surgical nurses are exposed to a variety of specific risks, which can contribute to higher stress and health deterioration [9], too.

For long time Bulgaria is facing nurses shortage and high turnover. The number of nurses per 100000 inhabitants shows the deepness of the problem. In 2016, there were 435 practicing nurses per 100000 inhabitants in Bulgaria [10] compared to 868 in the EU. This contributes to long working hours due to overtime or/and second work place. The night work, long working hours and work-related stressors may operate in interaction, resulting in more health symptoms and poor health.

The aim of the study was to follow the working time arrangements, stressors and health symptoms in hospital nurses in Sofia.

\section{METHODS}

\section{Study design}

A cross-sectional survey was conducted which included the 19 largest hospitals (> 150 beds) in Sofia, Bulgaria, as a part of a study of risk factors for health in health care. The survey was anonymous, selfadministered questionnaire was filled by the nurses at their workplaces. Overall 1302 nurses participated in the study, 1292 female and 10 male of average age $50.0 \pm 10.2$ years and average length of service $27.6 \pm 10.8$ years. Because of the small number, the male nurses were excluded from the analysis. Three groups were analyzed: nurses from departments, nurses from emergency and intensive care units and surgical nurses; their age, length of service and education are presented in Table 1 . The study was approved by the ethical committee of the National Center of Public Health and Analyses.

\section{Data collection}

The questionnaires gathered information about the demographic, physical and behavioral characteristics as well as the previous and current work schedules of the nurses, as shiftwork, night shifts, length of the shifts. Information was also collected on how many night shifts are worked per month: 0 nights per month, 1-2 nights per month, 3-4 nights per month, more than 5 nights per month. To assess the history of night work, the respondents reported the number of years they worked night shifts (including rotating and non-rotating night shifts). The participants also answered question on overtime worked in the hospital and how often it happened, whether they had a second job, and taking in account the overtime and second job how many hours on average they work per week. The average hours worked per week were specified as follows: $21-40$ hours, $41-50$ hours, $51-60$ hours and $>61$ hours/week.

Stress was assessed with a questionnaire based on the short version of the German Instrument for stressrelated job analyses [11]. The questionnaire included 30 items focused on stressors, as time pressure, uncertainty, frustration, problems in workflow due to supervisors and colleagues, social stressors as emotional dissonance with patients and their families and resources as autonomy, professional development, participation, social support from supervisors and colleagues, justice. Questions also about the subjective feeling of working under high strain, the need of maintaining constant concentration during work were introduced, as well as work related problems in the family life.

The nurses' health was rated using a 5-point scale as excellent, very good, good, fair and poor, the participants answered how often have they been emotionally and physically exhausted during the last 4 weeks [12] and completed a self-rated health questionnaire (17 health symptoms).

\section{Data analysis}

The data was introduced and processed with the SPSS 15.0 statistical package. ANOVA and Pearson correlation coefficient were applied for statistical analyses, and the significance level was set at $p<0.05$.

\section{RESULTS}

The shift work, night work, including 5 and more night shifts per month and the extended shifts were common among the studied nurses with the greatest deal of the emergency/ intensive care unit nurses, followed by department nurses (Table 2). Overtime was common, $33.5 \%$ of the studied nurses were working overtime more than 2 times per week and $28.8 \%$ worked at second health care establishment. The overtime together with the work at a second workplace contributed to long working hours of $51-60$ hours per week in $16.9 \%$ of the nurses and $>61$ hours in $11.1 \%$. A greater deal of the surgery nurses worked overtime, while the greater share of emergency and intensive care nurses had a second job. 
Table 1. Age, length of service and education of the female participants in the study

\begin{tabular}{|l|c|c|c|c|}
\hline & $\begin{array}{c}\text { Department nurses } \\
\mathrm{n}=\mathbf{8 2 6}(\mathbf{6 3 . 9 \% )}\end{array}$ & $\begin{array}{c}\text { Emergency/ intensive } \\
\text { care unit nurses } \\
\mathrm{n}=\mathbf{3 1 0}(\mathbf{2 4} \%)\end{array}$ & $\begin{array}{c}\text { Surgery nurses } \\
\mathrm{n=156}(\mathbf{1 2 . 1 \% )}\end{array}$ & $\begin{array}{c}\text { All nurses } \\
\mathrm{n}=\mathbf{1 2 9 2}\end{array}$ \\
\hline Age, years (mean \pm SD) & $50.9 \pm 10.1$ & $49.2 \pm 10.1$ & $46.6 \pm 9.9$ & $50.0 \pm 10.2$ \\
\hline Experience, years (mean \pm SD) & $28.4 \pm 10.7$ & $27.1 \pm 11.0$ & $24.3 \pm 10.8$ & $27.6 \pm 10.8$ \\
\hline Education, \% & & & & \\
Secondary education & 2.1 & 3.2 & 0 & 2.1 \\
College degrees & 48.3 & 42 & 39.1 & 45.7 \\
Higher education & 49.6 & 54.8 & 60.9 & 52.2 \\
\hline
\end{tabular}

Table 2. The share of the studied nurses (\%) working under the following time arrangement characteristics

\begin{tabular}{|l|c|c|c|c|c|}
\hline & $\begin{array}{c}\text { Department } \\
\text { nurses }\end{array}$ & $\begin{array}{c}\text { Emergency/ intensive } \\
\text { care unit nurses }\end{array}$ & Surgery nurses & All nurses & Pearson $\chi^{2} ; \mathbf{p}$ \\
\hline Shift work (\%) & 73.6 & 85.4 & 55.8 & 74.3 & $124.770 ; 0.000$ \\
\hline Night work (\%) & 61.4 & 78.3 & 26 & 61.3 & $124.770 ; 0.000$ \\
\hline$>5$ night shifts/month (\%) & 46.8 & 65.8 & 13.6 & 47.9 & $125.476 ; 0.000$ \\
\hline 12-hour shifts (\%) & 56.5 & 79.6 & 18.5 & 57.5 & $163.757 ; 0.000$ \\
\hline Overtime > 2 days/week (\%) & 35 & 21.7 & 49.4 & 33.5 & $54.288 ; 0.000$ \\
\hline Second job (\%) & 29.3 & 32.3 & 19.2 & 28.8 & $8.894 ; 0.012$ \\
\hline Working time in hours/week (\%) & & & & & \\
20-40 hours/week & 38.8 & 34.6 & 39.1 & 37.8 & \\
41-50 hours/week & 35 & 32.1 & 34.6 & 34.2 & \\
51-60 hours/week & 15.9 & 19.9 & 15.8 & 16.9 & NS \\
$>$ >61 hours/week & 10.3 & 13.4 & 10.5 & 11.1 & \\
\hline
\end{tabular}

About $90 \%$ of the nurses felt under strain (Figure 1 ), the job was requiring permanent concentration, at least 2 times/week the nurses felt emotional dissonance of working with patients. More than $50 \%$ of the nurses felt frustration, e.g. lack of enough time for patients because of lot of administration duties, and unsafe at their work places. More than $30 \%$ worked always under time pressure and felt uncertainty, e.g. taking decision without enough information at least 2 times/week. Great deal of the studied nurses considered their payment unsatisfactory. On the other hand, $94.5 \%$ of the nurses had social support from supervisors and colleague and $68.4 \%$ had opportunities for professional development; autonomy on their work had $36.5 \%$ and $34.4 \%$ considered there was justice in distribution of work between the staff.

There were no considerable differences in the ratings of stressors and resources between the three groups of nurses, but several items could be mentioned (Table 3). The share of nurses, rating to work under high strain, with high tempo of work, under emotional dissonance of patients, treat of violence and reproach of patients and their families was the highest with the emergency/intensive care nurses, while frustration with department nurses.Nurses working in the hospital departments were positive about the opportunities they are given for professional development.

The overall health was self-rated as good, $2.74 \pm$ 0.62 , with no significant differences concerning night work and long working hours. The ratings for emotional and physical exhaustion were high, with the highest levels with the emergency and intensive care units nurses, followed by department ones. The differences between the groups were significant for emotional exhaustion; while for physical exhaustion did not reach statistical significance (Table 4). The reported number of health symptoms was the highest with the nurses from the departments, followed by the group from the emergency and intensive care units, 


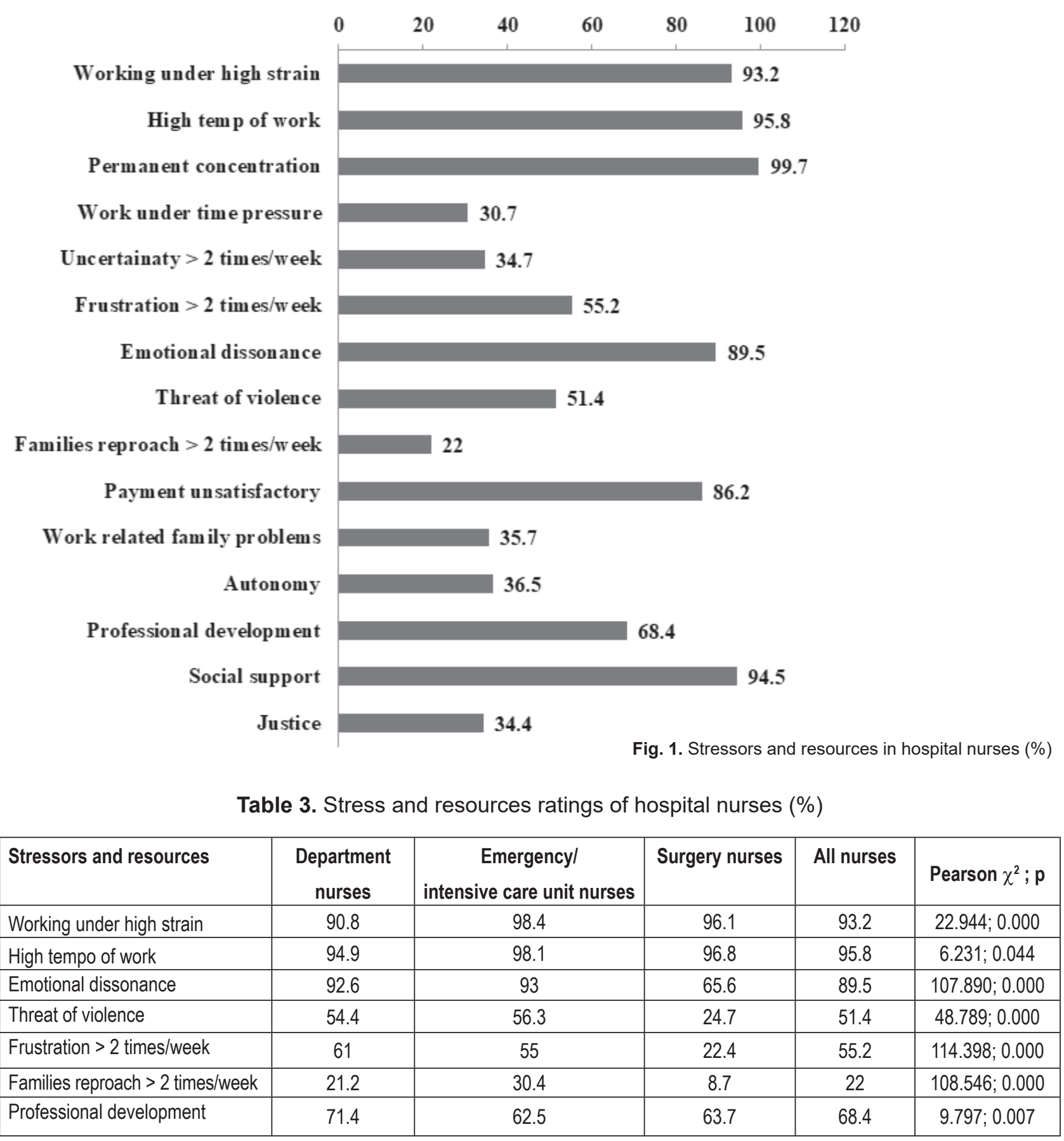

Table 4. Emotional and physical exhaustion, psychosomatic complaints in hospital nurses

\begin{tabular}{|l|c|c|c|}
\hline Variable & Department & $\overline{\mathbf{x}} \pm$ SD & \multicolumn{1}{|c|}{ F; $\mathbf{p}$} \\
\hline Emotional exhaustion & Surgery & $2.8 \pm 1.5$ & \\
& Emergency / lintensive care & $3.2 \pm 1.3$ & \\
& Department & $3.1 \pm 1.3$ & \\
\hline Physical exhaustion & Surgery & $3.2 \pm 1.2$ & \\
& Emergency / lintensive care & $3.4 \pm 1.1$ & \\
& Department & $3.3 \pm 1.2$ & \\
\hline Psychosomatic complaints & Surgery & $8.1 \pm 4.0$ & \\
& Emergency / lintensive care & $9.0 \pm 4.3$ & \\
& Department & $9.3 \pm 4.0$ & \\
\hline
\end{tabular}


$F=4.199 ; p=0.015$. The psychosomatic complaints increased significantly $(F=8,095, p<0.001)$ with the increase of working hours per week as follows: 8.7 \pm 3.9 ; $8.9 \pm 3.9$; $9.3 \pm 3.9$ and $10.8 \pm 4.2$ with work hours of $20-40 ; 41-50 ; 51-60$ and $>61$ consecutively.

The most frequent complains (> $60 \%$ of the respondents) were from frequent fatigue, anxiety, forgetting, pains in the muscles and bones, pains in the back, sleep problems (Table 5). More than $50 \%$ of the nurses reported dizziness and limb numbness and more than $30 \%$ - lack of mood, stomach problems and headache. Significant differences between the three groups were found for anxiety, dizziness, stomach problems, pains in the chest and quickly out of breath, with the highest share ratings with the department nurses, followed by emergency and intensive care nurses.

Emotional exhaustion, the key dimension of burnout, was determined by the time pressure, high strain, frustration and lack of autonomy (Table 6); while the physical exhaustion - by the same stressors plus the age in a highly significant model. The psychosomatic complaints were related to the time pressure, emotional dissonance with patients and their families, frustration and lack of justice and social support.

Table 5. The rate of the psychosomatic complaints of the nurses (\%)

\begin{tabular}{|l|c|c|c|c|c|}
\hline & $\begin{array}{c}\text { Department } \\
\text { nurses }\end{array}$ & $\begin{array}{c}\text { Emergency/intensive } \\
\text { care unit nurses }\end{array}$ & $\begin{array}{c}\text { Surgery } \\
\text { nurses }\end{array}$ & All nurses & Pearson $\chi^{2} ; \mathbf{p}$ \\
\hline Frequent fatigue & 74.1 & 73.6 & 69.5 & 73.4 & NS \\
\hline Forgetting & 69 & 68 & 74 & 69.3 & NS \\
\hline Pains in the muscles and bones & 71.8 & 72.6 & 67.5 & 71.5 & NS \\
\hline Pains in the back & 66.7 & 68.6 & 69.5 & 67.5 & NS \\
\hline Anxiety & 78.5 & 72.5 & 69.1 & 76 & $8.820 ; 0.012$ \\
\hline Lack of mood & 55.6 & 51.2 & 45.6 & 53.4 & NS \\
\hline Sleep problems & 67.0 & 68.5 & 59.2 & 66.4 & NS \\
\hline Dizziness & 61.5 & 54.7 & 47.4 & 58.2 & $12.624 ; 0.002$ \\
\hline Stomach ache & 49.9 & 42.9 & 30.5 & 46 & $20.998 ; 0.000$ \\
\hline Headache & 43.5 & 40.9 & 39.5 & 42.4 & NS \\
\hline Limb numbness & 59.9 & 57.6 & 51.3 & 58.3 & NS \\
\hline Pains in the chest & 48.5 & 45.8 & 28.3 & 45.4 & $21.034 ; 0.000$ \\
\hline Apathy & 29.4 & 31.4 & 28.7 & 29.8 & NS \\
\hline Quickly out of breath & 29.2 & 28.4 & 16.9 & 27.5 & $10.049 ; 0.007$ \\
\hline
\end{tabular}

Table 6. The determinants of emotional and physical exhaustion and psychosomatic complaints in nurses

\begin{tabular}{|c|c|c|c|c|}
\hline Variables & Determinants & $\beta$ & T & $p$ \\
\hline \multirow[t]{4}{*}{ Emotionally exhausted } & Time pressure & .191 & 5.973 & .000 \\
\hline & High strain & .209 & 6.804 & .000 \\
\hline & Frustration & .166 & 5.224 & .000 \\
\hline & Autonomy & -.119 & -3.831 & .000 \\
\hline \multicolumn{5}{|c|}{$r^{2}=18.00, F=51.137, p=0.000$} \\
\hline \multirow[t]{4}{*}{ Physically exhausted } & Time pressure & .196 & 6.015 & .000 \\
\hline & High strain & .212 & 6.807 & .000 \\
\hline & Frustration & .139 & 4.347 & .000 \\
\hline & Age & -.107 & -3.462 & .001 \\
\hline \multicolumn{5}{|c|}{$r^{2}=15.20, F=41.636, p=0.000$} \\
\hline \multirow[t]{6}{*}{ Psychosomatic complaints } & Time pressure & .171 & 4.679 & .000 \\
\hline & Justice & -.143 & -4.040 & .000 \\
\hline & Emotional dissonance & .102 & 2.914 & .004 \\
\hline & Frustration & .106 & 2.888 & .004 \\
\hline & Social support & -.093 & -2.648 & .008 \\
\hline & & & & \\
\hline
\end{tabular}




\section{DISCUSSION}

The shift schedules of more than $60 \%$ of the studied hospital nurses are rotating and include night work and in 50\% 12-hour shifts. The long working hours are common because of overtime and second job; and the increase of the working time correlates with higher number of night shifts. Shift working with more night shifts monthly and overtime hours weekly was earlier shown to contribute to impaired sleep and fatigue in the studied group of nurse [13]. The sleep impairment was more evident with the increase in the number of night shifts, while fatigue with the increase of working hours.

About $90 \%$ of the studied nurses felt under strain, worked with high speed and felt emotional dissonance of working with patients. More than $50 \%$ of the nurses felt frustration, e.g. lack of enough time for patients because of lot of administration duties. Moreover, nurses felt unsafe at their work places due to threat of violence. Furthermore, more than $30 \%$ worked always under time pressure and felt uncertainty, e.g. they had to make decisions without enough information at least 2 times/week.

The share of nurses, who reported to work under high strain, with high speed of work, feeling emotional dissonance of working with patients and being abused by patients/families, was the highest in the emergency and intensive care units. The nurses perform their roles in a high level of responsibility over their tasks and the consequences of possible errors; direct work with vulnerable persons; the need to confront unpredictable events, suffering, pain and death; the development of critical judgement regarding the actions produced after a medical diagnosis; etc. These can contribute to higher level of stress and more health conditions, and it is especially true taking in account the long working hours. Vandevala et al. [14] showed that employees, who worked more than $40 \mathrm{~h}$ per week in the intensive care unit, reported to experience higher levels of stressors, and later were associated with higher incidences of burnout and depression.

Our data also show high level of emotional and physical exhaustion with studied nurses, the highest with the emergency and intensive unit nurses. The emotional exhaustion component is considered as the crucial burnout dimension [15] and Vandenbroeck el al. [16] found that the emotional exhaustion was in strong negative associations with all assessed outcomes of individual well-being. Our data showed high number of psychosomatic complaints with the studied nurses, higher in comparison with that of physicians [17], followed during the study. The number of psychosomatic complaints was the highest with the department nurses, followed by the emergency and intensive care unit nurses. The number of psychosomatic complains with the nurses was highly significantly related to the working hours per week, nurses working more hours had more psychosomatic complaints. Nurses who often work overtime or without proper rest are more susceptible to higher absenteeism and deterioration in their health status [18]. The vast majority of the UK nurses worked 7.5$8 \mathrm{~h}$, which resulted from generally accepted work patterns in that country, but also from the concern of the management for work-life balance, patient and employee safety, and work efficiency [19]. Our data indicate the opposite, mainly 12-hour shifts, followed by a mixed system of 8-hour and 12-hour shifts, as well as overtime and/or second job, both contributing to long working hours weekly and insufficient recovery. Long weekly working hours ( $56 \mathrm{~h} /$ week and $61 \mathrm{~h} /$ week for women and men, respectively) have been shown for Brazilian nurses [20], explained later with the lower wages and having a second job and commented in regards to work overload and intention to quit the profession [21].

Health care workers are exposed to various occupational stress factors, most of which susceptible to reduction. Ettorre and Greco [5] proposed stress management programs aimed to improve work context factors associated with occupational stress and in such way to minimize the impact of work related stress on workers. Our data show that the occupational stress and shift work, especially night work and long working hour should be carefully managed.

In conclusion, the work-related stress and working time arrangements raise health concerns for the occupational health of the studied hospital nurses. Emotional exhaustion, the key dimension of burnout, was strongly related to the time pressure, high strain, frustration and lack of autonomy, while the physical exhaustion was related to the same stressors plus the age. The number of psychosomatic complaints was high, the highest with the nurses with the longest working time. Urgent preventive measures are needed to control stress and manage the shift work, both night work, overtime and long working hours.

Disclosure summary: The authors have nothing to disclose.

\section{REFERENCES}

1. Sheward L, Hagen S, Macleod M, Ball J. The relationship between UK hospital nurse staffing and emotional exhaustion and job dissatisfaction. J Nurs Manag. 2005;13:51-60, https:// doi.org/10.1111/j.1365-2834.2004.00460.x. 
2. Khamisa N, Peltzer K, Dragan Ilic D, Brian Oldenburg B. Work related stress, burnout, job satisfaction and general health of nurses: A follow-up study. Int J Nursing Practice 2016; 22 (6): 538-545. https://doi.org/10.1111/ijn. 12455

3. Freimann T, Merisalu E. Work-related psychosocial risk factors and mental health problems amongst nurses at a university hospital in Estonia: A cross-sectional study. Scand J Publ Health 2015; 43: 447-452. https://doi. org/10.1177/1403494815579477

4. Jones G, Hocine M, Salomon J et a;. Demographic and occupational predictors of stress and fatigue in French intensivecare registered nurses and nurses' aides: A cross-sectional study. International Journal of Nursing Studies 2015; 52:250259. https://doi.org/10.1016/j.ijnurstu.2014.07.015

5. Ettorre G, Greco M. Healthcare Work and Organizational Interventions to Prevent Work-related Stress in Brindisi, Italy. Safety and Health at Work 2015; 6(1): 35-38. https://doi. org/10.1016/j.shaw.2014.10.003

6. Lothschuetz Montgomery K, Geiger-Brown J. Is it time to pull the plug on 12-hour shifts?: Part 2. Barriers to change and executive leadership strategies. J Nurs Adm 2010; 40(4); 147-149.

7. Lakanmaaa RL, Suominenb T, Perttilä $J$ et al. Competence requirements in intensive and critical care nursing - Still in need of definition? A Delphi study. Intensive Crit Care Nurs. 2010;28:329-336.

8. Ceballos-Vásquez P, Rolo-González G, Hérnandez-Fernaud $E$ et al. Psychosocial factors and mental work load: a reality perceived by nurses in intensive care units. Rev Lat Am Enfermagem. 2015 Feb-Apr; 23(2): 315-322. doi: 10.1590/01041169.0044.2557

9. Uğurlu Z, Karahan A, Ünlü H et al. The Effects of Workload and Working Conditions on Operating Room Nurses and Technicians.Work place health and safety 2015; 63 (9): 399407. https://doi.org/10.1177/2165079915592281

10. Practicing nurses, per 100000 population. Health care personnel statistics. Eurostat. https://ec.europa.eu/eurostat/ statistics-explained/index.php/Healthcare_personnel_statistics_-_nursing_and_caring_professionals

11. Keller M, Bamberg E, Böhmert M, Nienhaus A. Entwicklung eines Instruments zur stressbezogenen Arbeitsanalyse für
Klinikärztinnen und -ärzte (ISAK). Zeitschrift für Arbeitswissenschaft 2010;64:337-353.

12. SHORT COPSOQ II questionnaire. National Centre for the Working Environment, Denmark

13. Cekova, I., Stoyanova, R., Dimitrova, I., Vangelova, K. Sleep and fatigue in nurses in relation to shift work. Advances in Intelligent Systems and Computing Proceedings of 20th congress of International Ergonomics association 2018:2(819):186-193.

14. Vandevala T, Pavey L, Chelidoni $O$ et al. Psychological rumination and recovery from work in intensive care professionals: associations with stress, burnout, depression and health. Journal of Intensive Care 2017,5:16. doi:org/10.1186/s40560017-0209-0

15. Demerouti E, Bakker AB, Nachreiner F, Schaufeli WB. The job demands-resources model of burnout. Journal of Applied Psychology 2001; 86: 499-512.

16. Vandenbroeck S, Van Gerven E, De Witte H, Vanhaecht K, Godderis L. Burnout in Belgian physicians and nurses. Occup Med (Lond). 2017;67(7):546-54. doi:org/10.1093/occmed/kqx126

17. Vangelova K., Dimitrova I., Cekova I., Stoyanova R. Workrelated risk factors in hospital physicians. Ukrainian Journal of Occupational Health 2019.

18. Sheward L, Hagen S, Macleod M, Ball J. The relationship between UK hospital nurse staffing and emotional exhaustion and job dissatisfaction. J Nurs Manag. 2005;13:51-60, https:// doi.org/10.1111/j.1365-2834.2004.00460.x.

19. Royal College of Nursing. Working well: A call to employers: A summary of the RCN Working well survey into the wellbeing and working lives of nurses. London: The College; 2000.

20. Fernandes JC, Portela LF, Rotenberg L, Griep RH. Working hours and health behaviour among nurses at public hospitals. Rev Latino-Am Enfermagem. 2013;21(5):1104-11.

21. De Oliveira DR, Griep RH, Portela LF, Rotenberg L. Intention to leave profession, psychosocial environment and self-rated health among registered nurses from large hospitals in Brazil: a cross-sectional study. BMC Health Serv Res. 2017;17(1):21. https://doi.org/10.1186/s12913-016-1949-6. 